\title{
Babies by bar-press: Maternal behavior in the rat'
}

\author{
W. E. WILSONCROFT, SAN FERNANDO VALLEY STATE \\ COLLEGE, Northridge, California 91324
}

Pregnant rats were trained to press a bar for food rewards: Postpartum these Ss were tested when each bar-press delivered a rat pup (S's own or foster) into the food cup. Ss repetitively bar-pressed, snatched up the pup as it tumbled down the chute and retrieved the pup into the adjacent nest box. Ss lived with 6 nursing pups but bar-pressed for hundreds: E removed all but 6 pups from the nest box after $S$ had accumulated about 20. Maximal performance was 684 responses in a 3-h period. This technique is currently being used to study weaning and hormonal factors involved in the rat's maternal motivation.

Early studies by Szymansky (1918) and Simons (1924) indicated that mother rats would learn complex mazes to be with their litters. Later, Nissen (1930) and Warden (1931), employing electric grid obstruction apparatus, found that mother rats would perform more grid crossings to get to their litters than they would when the reinforcement was satiation of thirst, hunger, sex, or exploration. Curiously, no reports have yet related this maternal motivation to the classical bar-pressing situation.

A related topic is the retrieving behavior of mother rats. Postpartum rats will routinely retrieve their own or foster pups into their nest (Wiesner \& Sheard, 1933; Beach \& Jaynes, 1956). This behavior is maximal in the days just following parturition. Indeed, so strong is this response that after collecting all available pups, mother rats will sometimes retrieve their own appendagesi.e., tails and paws (Wilsoncroft \& Shupe, 1965). In the present study, after bar-pressing was reinforced with presentation of pups, it was anticipated that Ss would retrieve the pups into their nest boxes. The persistence of the bar-pressing and the retrieval behavior can help us measure the rat's maternal motivation.

\section{METHOD}

Pregnant rats $(\mathrm{N}=5)$ were trained to press a bar to obtain food rewards (Noyes Precision Pellets). Ss were fed 5-6 Purina pellets per day in their nest boxes. The bar-pressing box measured $2 \mathrm{ft}$ square, with the bar and reward cup on the wall opposite the entrance door. Ss were housed in 1-ft-square nest boxes and during testing this nest box opened directly into the test box with bar. Food pellets, and later rat pups, were delivered down the reward chute after being pushed with a brush from a Davis Universal Feeder (Model 320); an Esterline-Angus recorder was used to mark bar-presses and intervals.

A group of nonexperimental mother rats $(\mathrm{N}=10)$ provided foster pups that were the same age as those of the experimental Ss: The experimental Ss nursed six pups throughout the study, their extra pups were removed to foster mothers on the day of parturition. On the day following parturition Ss' litters were removed and Ss were then allowed to enter the test box. Their first six bar-presses were rewarded with food pellets; all other bar-presses were rewarded with pups. First the Ss got their own six pups, then foster pups of equal age were delivered.

\section{RESULTS}

The Ss differed in their initial reactions to being rewarded with pups rather than food pellets. Two Ss immediately picked up the pup and retrieved it to the nest box. The other Ss ignored the first few pups but continued to press the bar. This resulted in an accumulation of bodies in the food cup but within a few minutes all Ss began retrieving the pups into the nest box. $\mathrm{E}$ removed all

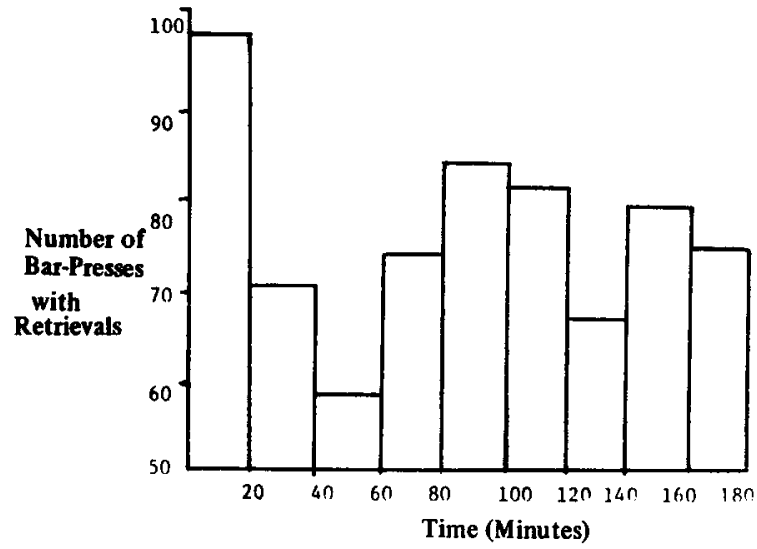

Fig. 1. Number of bar-presses with retrievals per 20-min interval over $3 h$ test. S5.

but 6 pups from the nest box after $S$ had collected about 20 pups. This procedure did not seem to slow down the determined behavior of the Ss except on the first few removals.

The Ss engaged in a stereotyped sequence of behaviors after retrieving began: Bar pressing was followed by picking up the pup as it fell from the delivery chute into the reward cup, the pup was then carried across the test box and into Ss' nest box. This behavior continued for $3 \mathrm{~h}$.

Figure 1 shows the response pattern for $S 5$, our best performer. The figure shows that the rate of bar-pressing diminishes rapidly at first but then rebounds and remains fairly high over the $3 \mathrm{~h}$ of testing. The only real extinction appeared to occur in Es who got tired of removing the pups from the nest box and filling the delivery apparatus. The total number of bar-presses and retrievals was $684-$ or about one complete behavioral sequence every $15 \mathrm{sec}$ for $3 \mathrm{~h}$. Ss carried each pup about $3 \mathrm{ft}$ so that this $S$ carried pups over $2,000 \mathrm{ft}$ during the testing and returned an equal distance to the bar after each retrieval.

The other Ss all bar-pressed for hundreds of pups also; the lowest number of responses over a 3-h period was 247. Figure 2 shows the mean number of bar-presses with retrievals for the five Ss run to date. This figure shows that the rate of bar-pressing remains high throughout testing. Comparison of Fig. 1 and Fig. 2 illustrates some of the variability.

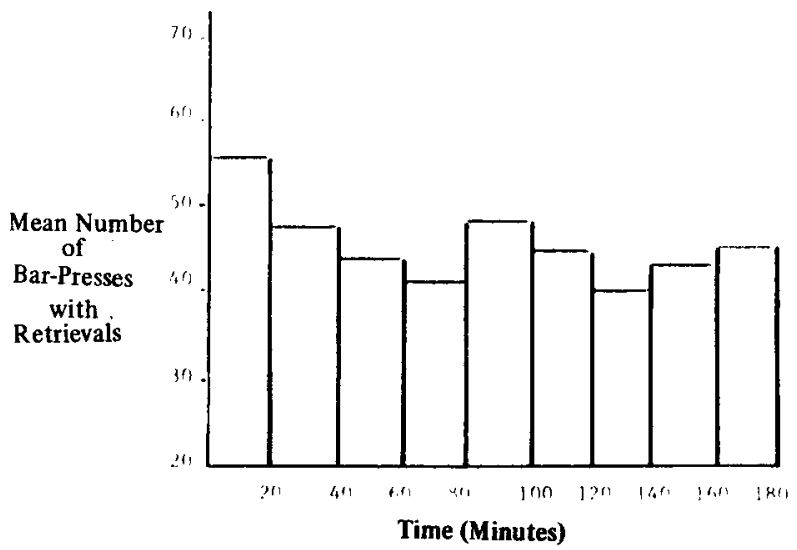

Fig. 2. Mean number of bar-presses with retrievals per 20-min interval $(\mathbf{N}=5)$. 


\section{DISCUSSION}

The Ss did not seem to differentiate their own pups from foster pups of the same age. No increased latency or hesitation to retrieve was observed in connection with these alien animals but there is not enough data to substantiate this point: Since the Ss' own pups were mixed with the fosters after the first removal during testing, there was only one chance to observe this own/foster distinction in each test-i.e., on the initial presentation of the first foster pup.

The pups in this study survived the handling very well and no pups were lost during the study despite the rather hazardous duty of being pushed out of the feeder, falling down the chute into the food cup, being picked up and carried to the nest by Ss, and being returned again and again by $E$ to the feeder mechanism.

This technique affords a useful method for studying maternal behavior. Currently we are studying the decline of maternal motivation during the first 10 postpartum days and testing the effects of estrogen injections.

\section{REFERENCES}

BEACH, F, A., \& JAYNES, J. Studies of maternal retrieving in rats: III. Sensory cues involved in the lactating female's response to her young. Behaviour, 1956, 10, 104-125.

NISSEN, H. W. A study of matemal behavior in the white rat by means of the obstruction method. Journal of Genetic Psychology, 1930, 37, 377-393.

SIMONS, R. The relative effectiveness of certain incentives in animal learning. Comparative Psychological Monographs, 1924, 2, No. 7.

SZYMANSKI, J. S. (1918). Cited in N. L. Munn, Handbook of psychological research on the rat. New York: Houghton-Mifflin, 1950, p. 311.

WARDEN, C. J. Animal motivation studies: The albino rat. New York: Columbia, 1931.

WIESNER, B. P., \& SHEARD, N. M. Maternal behavior in the rat Edinburgh: Oliver \& Boyd, 1933.

WILSONCROFT, W. E., \& SHUPE, D. V. Tail, paw and pup retrieving in the rat. Psychonomic Science, 1965, 3, 494.

$$
\text { NOTE }
$$

1. Paper presented at WPA Convention, San Diego, 1968. This research is supported by an NSF institutional grant through the San Fernando Valley State College Foundation. 